\title{
Artificial cathode solid electrolyte interphase to endow highly stable lithium storage of $\mathrm{FeF}_{2}$ nanocrystals
}

\author{
Ming Chen, Liang Zhao, Xiaomin Li, Xuejiao Liu, Jiantao Zai", Rongrong Qi ${ }^{*}$ and Xuefeng Qian*
}

\begin{abstract}
Iron difluoride $\left(\mathrm{FeF}_{2}\right)$ is considered a highcapacity cathode material for lithium-ion batteries. However, its specific capacity and stability are limited by the poor electrochemical kinetics of conversion reactions. Herein, the conversion reaction is confined in a localized nanosized space by encapsulating $\mathrm{FeF}_{2}$ nanoparticles in polymer gelatin. The $\mathrm{FeF}_{2}$ nanocrystal-coated polyvinylidene fluoride-based layer (defined as $\mathrm{FeF}_{2} @ 100 \% \mathrm{G}-\mathbf{4 0} \% \mathrm{P}$ ) was synthesized by glucoseassisted in-situ gelatinization to construct an artificial cathode solid electrolyte interphase via a solvothermal process. Thanks to the improved kinetics of the localized conversion reaction, the obtained $\mathrm{FeF}_{2} @ 100 \% \mathrm{G}-40 \% \mathrm{P}$ electrodes show good cyclic stability (313 $\mathrm{mA} \mathrm{h}^{-1}$ after 150 cycles at $100 \mathrm{~mA} \mathrm{~g}^{-1}$, corresponding to a retention of $80 \%$ ) and a high rate performance $\left(186.6 \mathrm{~mA} \mathrm{~h} \mathrm{~g}^{-1}\right.$ at $\left.500 \mathrm{~mA} \mathrm{~g}^{-1}\right)$.
\end{abstract}

Keywords: $\mathrm{FeF}_{2}$ nanocrystals, artificial PVDF-based CEI layer, cyclic stability, lithium-ion batteries

\section{INTRODUCTION}

Lithium-ion batteries (LIBs) are considered vital energy storage devices $[1,2]$. To meet the demand for high energy density, researchers have developed high-capacity cathode materials for LIBs, such as chalcogenides $\left(\mathrm{S} / \mathrm{Li}_{2} \mathrm{~S}\right.$ [3], $\mathrm{Se} / \mathrm{Li}_{2} \mathrm{Se}$ [4]), and fluorides $\left(\mathrm{MF}_{x}\right.$ [5-10]). Iron difluoride $\left(\mathrm{FeF}_{2}\right)$ as a conversiontype cathode material has been extensively studied due to its high theoretical capacity of $571 \mathrm{~mA} \mathrm{~h} \mathrm{~g}^{-1}$ and energy density of $1519 \mathrm{~W} \mathrm{~h} \mathrm{~kg}^{-1}$ for LIBs. However, the agglomeration of conversion products of active materials, the electrochemical sintering, and severe voltage hysteresis phenomenon commonly occur in conversion-type lithium storage materials, leading to the loss of specific capacities. Furthermore, the large bandgap of $\mathrm{FeF}_{2}$ induced by the high ionic state of metal-F bonds results in its electrical insulator nature, which is harmful to lithium storage performance [11]. Various novel strategies have been attempted to improve the electron conductivity and stabilize the interfacial layer of active materials and electrolytes. Recently, the method of encapsulating the transitional $\mathrm{MF}_{x}$ with a carbonous shell (TMF@C) has been shown to be an effective strategy to achieve high electrochemical performance of fluoride [12,13]. For instance, $\mathrm{FeF}_{2} @ \mathrm{C}$ nanorods fabricated via a one-pot thermal reaction of ferrocene and polyvinylidene fluoride (PVDF) can significantly improve their cycling stability. However, its exces- sively thick encapsulation layer limits the diffusion of lithium ions into the electrode $[13,14]$. Additionally, the decomposition of $\mathrm{MF}_{x}$ at high temperatures is a massive challenge for the synthesis of TMF@C [15]. Another method is to stabilize the interface with Li salt composites [16,17]. Recently, Pasta's group [18] revealed that an in situ-formed cathode solid electrolyte interphase (CEI) layer could significantly improve the cycling stability of $\mathrm{FeF}_{2}$ nanorods. However, the quality of the CEI layer strongly depends on the composition of the electrolyte and the working conditions. The reported high-quality CEI layer can only be generated in the ionic liquid-based electrolytes at $50^{\circ} \mathrm{C}$ and it fails in commonly used $\mathrm{LiPF}_{6} /$ ethylene carbonate:dimethyl carbonate electrolytes. Fuoroethylene carbonate (FEC) is usually used as an additive in the electrolyte of rechargeable batteries to form a high-quality CEI for the cathode. Wu et al. [19] reported an electrolyte with a high content of FEC, which formed a robust fluorinated CEI to passivate the surface of the $\mathrm{Na}_{2 / 3} \mathrm{Ni}_{1 / 3^{-}}$ $\mathrm{Mn}_{2 / 3} \mathrm{O}_{2}$ cathode, ensuring long cycling stability. However, fabricating an elastic, thin, and homogeneous CEI layer on active materials via a gentle synthesis method is still challenging [20]. PVDF with high thermal stability and sufficient strength can effectively prevent slumping and cracking of active particles and is an ideal material for the binder and porous separator of liquid LIBs.

Herein, a PVDF-based artificial CEI layer prepared through in-situ gelatinization was coated on $\mathrm{FeF}_{2}$ nanocrystals (defined as $\mathrm{FeF}_{2} @ 100 \% \mathrm{G}-40 \% \mathrm{P}$ ) via a one-step solvothermal process. Glucose was used as the reducing agent to regulate the structure of $\mathrm{FeF}_{2}$ in this reaction. Thanks to the improved kinetics of the localized conversion reaction in Scheme 1, the $\mathrm{FeF}_{2} @ 100 \% \mathrm{G}$ $40 \% \mathrm{P}$ electrodes exhibited a robust cycling performance of $313 \mathrm{~mA} \mathrm{~h} \mathrm{~g}^{-1}$ after 150 cycles at $100 \mathrm{~mA} \mathrm{~g}^{-1}$, corresponding to a retention of $80 \%$ and a high rate capacity $\left(186.59 \mathrm{~mA} \mathrm{~h} \mathrm{~g}^{-1}\right.$ at $\left.500 \mathrm{~mA} \mathrm{~g}^{-1}\right)$.

\section{EXPERIMENTAL SECTION}

\section{Synthesis of $\mathrm{FeF}_{2}$ and PVDF-FeF $\mathrm{F}_{2}$ composites}

$\mathrm{FeF}_{3} \cdot 3 \mathrm{H}_{2} \mathrm{O} \quad(180 \mathrm{mg})$ and $D(+)$-glucose $(180 \mathrm{mg}, \quad 100 \mathrm{wt} \%$ $\mathrm{FeF}_{3} \cdot 3 \mathrm{H}_{2} \mathrm{O}$ ) were milled to obtain a homogeneous reactant mixture and stirred vigorously for $1 \mathrm{~h}$ in butyl-alcohol $(75 \mathrm{~mL})$ at room temperature. The suspension was transferred into a Teflon-lined $100-\mathrm{mL}$ stainless-steel autoclave reactor. After being subsequently sealed, the reactor was heated at $180^{\circ} \mathrm{C}$ for

Shanghai Electrochemical Energy \& Research Centre State Key Laboratory of Metal Matrix Composites, Shanghai Jiao Tong University, Shanghai 200240, China

* Corresponding authors (emails: zaijiantao@sjtu.edu.cn (Zai J); rrqi@sjtu.edu.cn (Qi R); xfqian@sjtu.edu.cn (Qian X)) 


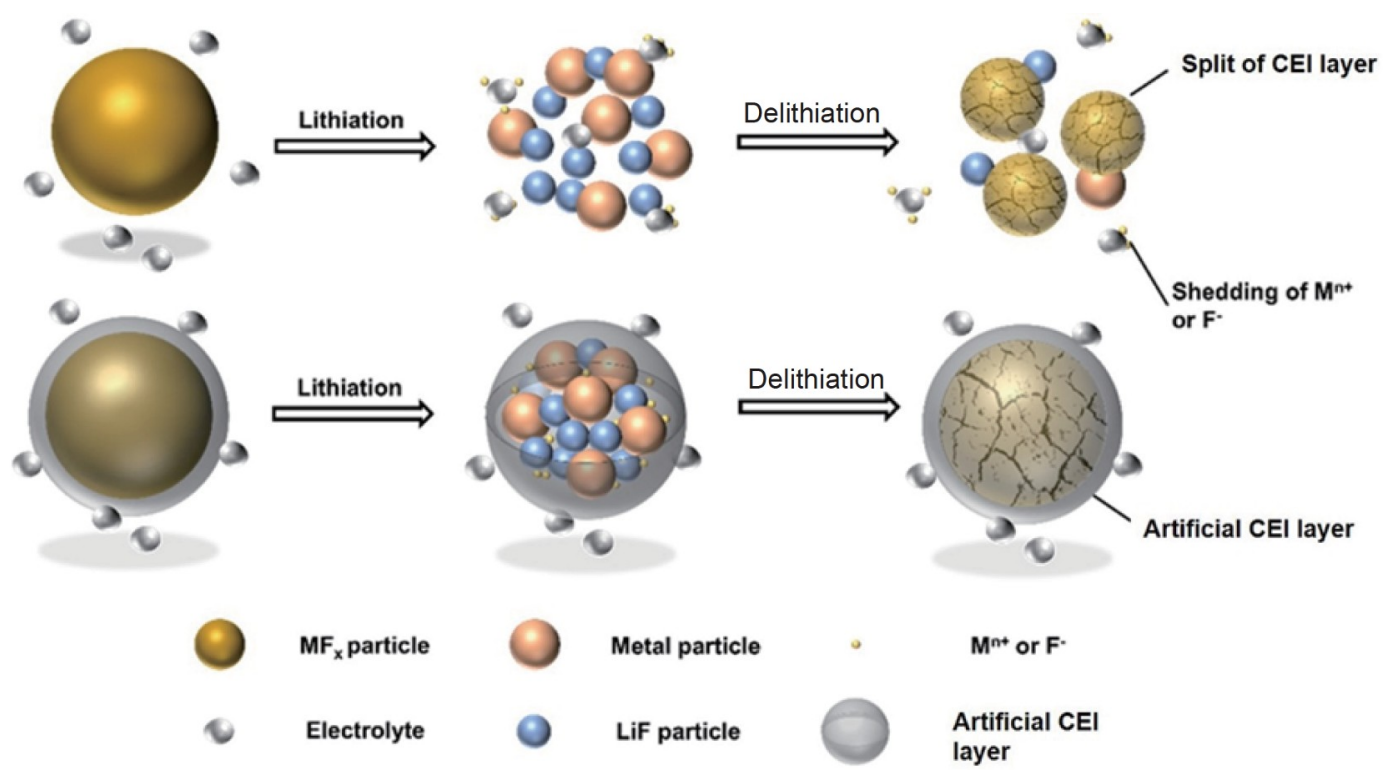

Scheme 1 The artificial CEI layer restricts the agglomeration of the conversion products, the rupture, and the shedding of the active materials.

$24 \mathrm{~h}$ in an oven. The product was cooled to room temperature and washed thrice with absolute ethanol. The products were labeled $\mathrm{FeF}_{2} @ x \% \mathrm{G}$ depending on the ratio of glucose $(10 \%, 20 \%$, $60 \%, 100 \%, 150 \%$, and $200 \%) . \mathrm{FeF}_{3} \cdot 3 \mathrm{H}_{2} \mathrm{O}(180 \mathrm{mg}), D(+)$-glucose $\left(180 \mathrm{mg}\right.$ ), and PVDF ( $y$ wt $\%$ of $\mathrm{FeF}_{3} \cdot 3 \mathrm{H}_{2} \mathrm{O}$ ) were milled to a homogeneous reactant mixture and reacted under the same conditions as $\mathrm{FeF}_{2} @ x \% \mathrm{G}$. The products were named $\mathrm{FeF}_{2} @ 100 \%$ $\mathrm{G}-y \% \mathrm{P}(10 \%, 20 \%, 40 \%$ and $60 \%)$.

\section{Characterization}

The morphology and structure of the samples were characterized on a D/max $2550 \mathrm{VL} / \mathrm{PC}$ diffractometer (Rigaku, Japan) with $\mathrm{Cu}$ $\mathrm{Ka}$ radiation $(40 \mathrm{kV}, 30 \mathrm{~mA}, \lambda=1.5418 \AA)$ and JEOL JEM2100F. Raman spectra were measured by Raman microscopy at $532 \mathrm{~nm}$. The pore size distribution and specific surface areas were calculated by an NOVA 2200e analyzer. X-ray photoelectron spectroscopy (XPS) was conducted with a Versa Probe PHI5000 multi-X-ray photoelectron spectrometer (ULVAC-PHI Inc., Japan), and the calibration was based on the $\mathrm{C}$ 1s (binding energy $-284.8 \mathrm{eV}$ ) peak.

\section{Electrochemical measurements}

Active materials (70 wt\%), carbon black (15wt\%, Super-P, Timcal), and binder (15 wt\% PVDF) were mixed in $\mathrm{N}$-methylpyrrolidinone (NMP) to form a slurry that was coated on aluminum foil and then dried for $8 \mathrm{~h}$ at $80^{\circ} \mathrm{C}$. The typical mass loading of the active materials was about $1 \mathrm{mg} \mathrm{cm}^{-2}$. Half-cells were assembled using CR2016 coin cells for LIBs in an argonfilled glove box $\left(\mathrm{O}_{2} \leq 0.1 \mathrm{ppm}, \mathrm{H}_{2} \mathrm{O} \leq 0.01 \mathrm{ppm}\right), 1 \mathrm{~mol} \mathrm{~L}^{-1}$ lithium trifluorosulfonamide salt (LiTFSI) in a mixture of FEC/ ethyl methyl carbonate (3:7 by vol\%) as the electrolyte, and polypropylene membrane (UBE Industries Ltd.) as the separator. Galvanostatic discharge/charge measurements were performed on a LAND-CT2001A system in the voltage range of $1.0-4.0 \mathrm{~V}$ (vs. $\mathrm{Li}^{+} / \mathrm{Li}$ ) at room temperature. Cyclic voltammetry $(\mathrm{CV})$ was performed using an electrochemical workstation (ZAHNER Zennium) at $0.3 \mathrm{mV} \mathrm{s}^{-1}$.

\section{RESULTS AND DISCUSSION}

\section{Structure and morphology}

The crystal structures of $\mathrm{FeF}_{2} @ x \% \mathrm{G}$ were characterized by X-ray diffraction (XRD) and scanning electron microscopy (SEM), as shown in Fig. 1a-f. The products obtained by the solvothermal reaction have good crystallinity. It can be seen from XRD that when the glucose content is $10 \%$, the sample shows a crystallization peak of $\mathrm{FeF}_{3} \cdot 0.33 \mathrm{H}_{2} \mathrm{O}$ (JCPDS No. 076-1262), and when the glucose content is higher than $20 \%$, the product is totally converted to rutile structure $\mathrm{FeF}_{2}$ (JCPDS No. 045-1062), and no peak of $\mathrm{FeF}_{3} \cdot 0.33 \mathrm{H}_{2} \mathrm{O}$ can be observed. Previous reports indicated that $\mathrm{FeF}_{3} \cdot 3 \mathrm{H}_{2} \mathrm{O}$ was dehydrated to form small nanoparticles at $180^{\circ} \mathrm{C}$, followed by the formation of $\mathrm{FeF}_{3} \cdot 0.33 \mathrm{H}_{2} \mathrm{O}$ nanorods [21-23]. The presence of a small amount of glucose partially reduced $\mathrm{Fe}^{3+}$ to $\mathrm{Fe}^{2+}$ (Fig. 1f). Lack of passivation caused oriented growth of $\mathrm{FeF}_{2}$ and formation of cluster-like structures during cooling [24]. An increase in glucose feed ratio further reduced the $\mathrm{Fe}^{3+}$, and excess glucose as a surfactant guided the formation and aggregation of the particles, and the $\mathrm{FeF}_{2}$ was completely passivated into nanoparticles. These nanoparticles aggregated in different ways to form two morphologies. The overall morphologies of $\mathrm{FeF}_{2}$ obtained with PVDF are nearly the same as those obtained at $20 \%$ and $100 \%$, indicating that PVDF has nearly no effect on the growth mechanism of $\mathrm{FeF}_{2}$ (Fig. S1). This indicates that the self-assembly results of the material should be attributed to glucose instead of PVDF.

Transmission electron microscopy (TEM) was used to analyze the micromorphology of the composite material. As shown in Fig. 2, the material is made up of small particles with a size close to $10 \mathrm{~nm}$. The presence or absence of PVDF makes an essential difference on the micro profiles. The PVDF makes the material smoother, and regular layered structures appear in high-resolution TEM (HRTEM). HRTEM shows that the interplanar spacing of the compound is $0.27 \mathrm{~nm}$ (corresponding to the (101) plane of $\mathrm{FeF}_{2}$ ). From the HRTEM image (Fig. 2f), the PVDF layer of the $\mathrm{FeF}_{2} @ 100 \% \mathrm{G}-40 \% \mathrm{P}$ sample can be seen to be uni- 

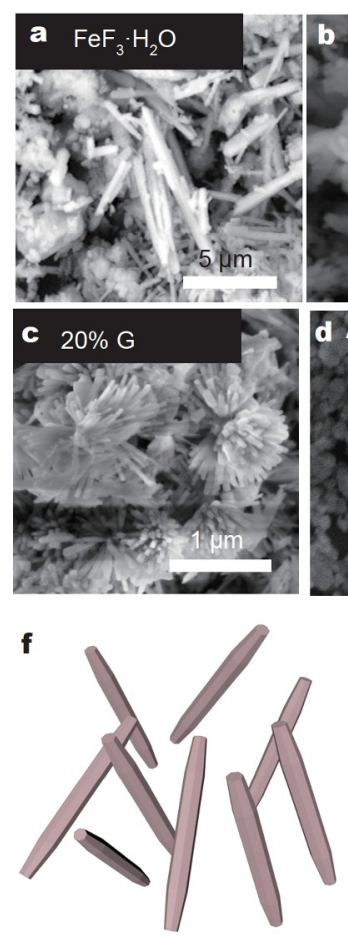

Pure $\mathrm{FeF}_{3} \cdot \mathrm{H}_{2} \mathrm{O}$
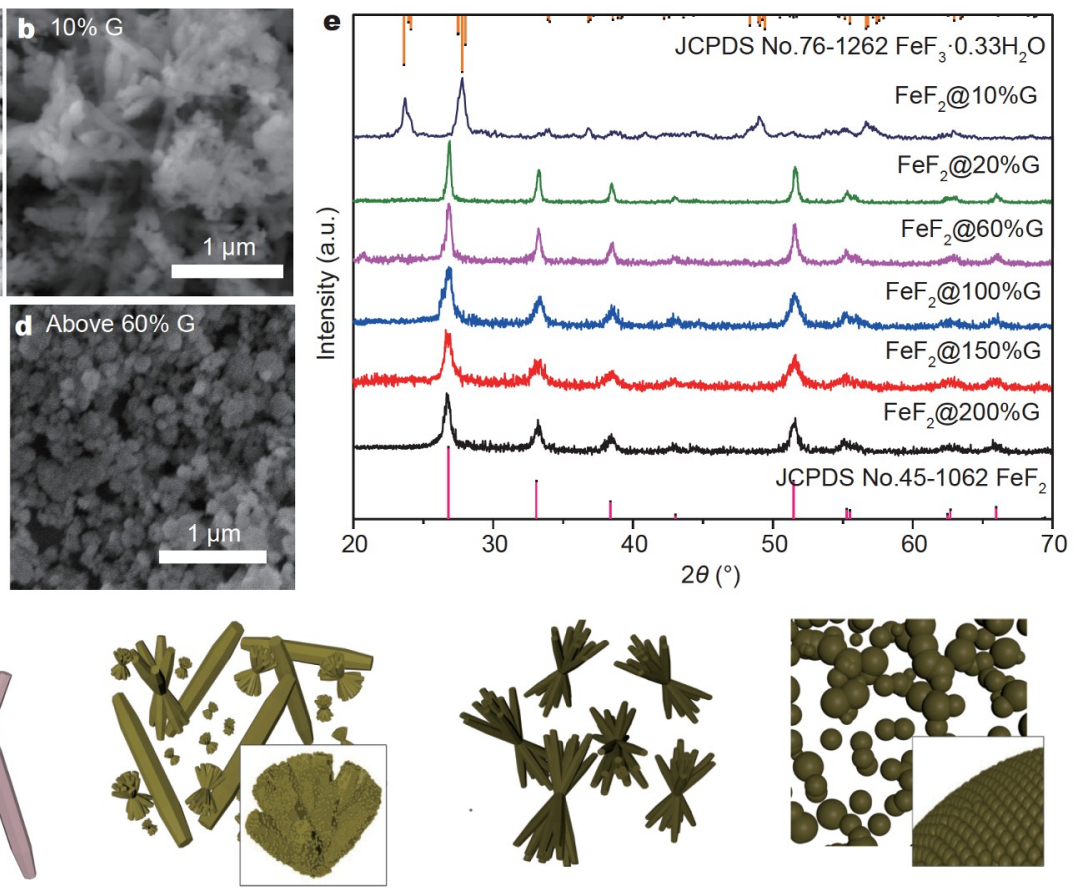

$10 \%$ glucose

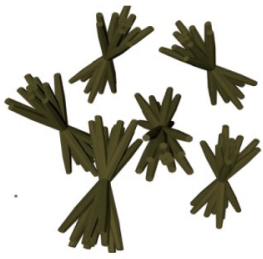

$20 \%$ glucose

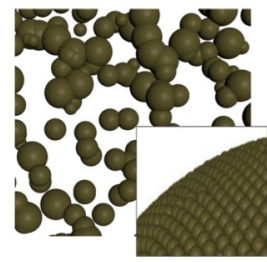

Above $60 \%$

Schematic of the product with the increase of glucose feed ratio

Figure 1 (a) SEM image of $\mathrm{FeF}_{3} \cdot 3 \mathrm{H}_{2} \mathrm{O}$; (b-d) $\mathrm{SEM}$ images of $\mathrm{FeF}_{2} @ 10 \% \mathrm{G}, \mathrm{FeF}_{2} @ 20 \% \mathrm{G}$ and $\mathrm{FeF}_{2} @ 40 \% \mathrm{G}$, respectively; (e) XRD spectra; (f) product simulation diagram with increasing amount of glucose.
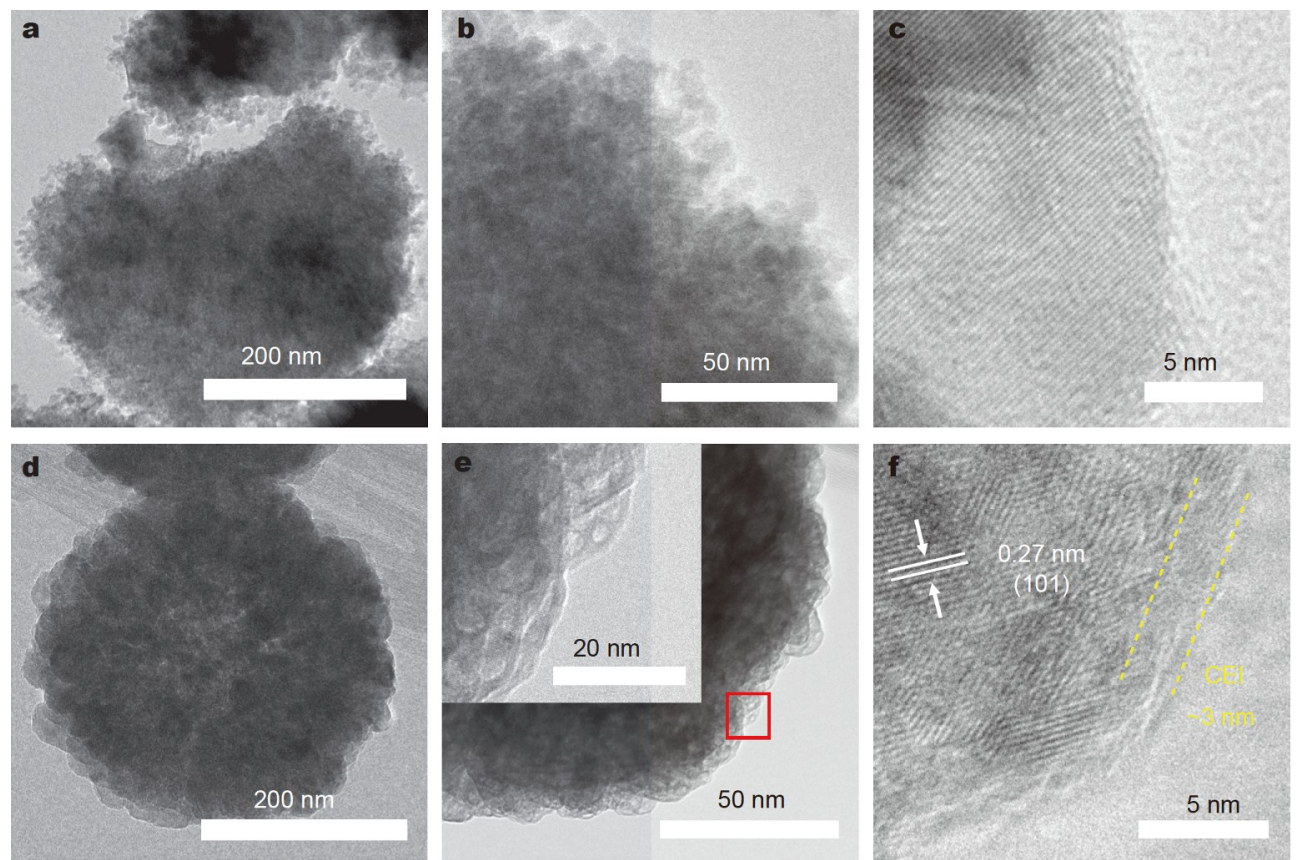

Figure 2 (a, b) TEM, (c) HRTEM images of $\mathrm{FeF}_{2} @ 100 \% \mathrm{G}$; (d, e) TEM, and (f) HRTEM images of FeF $\mathrm{F}_{2} @ 100 \% \mathrm{G}-40 \% \mathrm{P}$.

formly coated on the $\mathrm{FeF}_{2}$ nanoparticles, and the thickness of the PVDF layer is about $3 \mathrm{~nm}$. Fig. S2 shows the scanning transmission electron microscopy-energy dispersive X-ray spectroscopy (STEM-EDX) elemental mapping of Fe, F, and C.

XPS and Raman spectroscopy were used to study the effect of PVDF on the chemical composition of the $\mathrm{FeF}_{2} @ 10 \% \mathrm{G}$,
$\mathrm{FeF}_{2} @ 100 \% \mathrm{G}$, and $\mathrm{FeF}_{2} @ 100 \% \mathrm{G}-40 \% \mathrm{P}$ electrodes. Fig. 3a-d show the Fe 2p, O 1s, F 1s, and C 1s peaks of the four electrode materials. For Fe $2 \mathrm{p}$ XPS, $2 \mathrm{p}_{3 / 2}$ at $\sim 712 \mathrm{eV}$ and $2 \mathrm{p}_{1 / 2}$ at $\sim 725 \mathrm{eV}$ components of $\mathrm{Fe}^{2+}$ were observed. The difference is that $\mathrm{FeF}_{2} @ 10 \% \mathrm{G}$ has a certain shift. In PVDF-containing electrodes, the core level spectra of the surface F 1s show the two strongest 

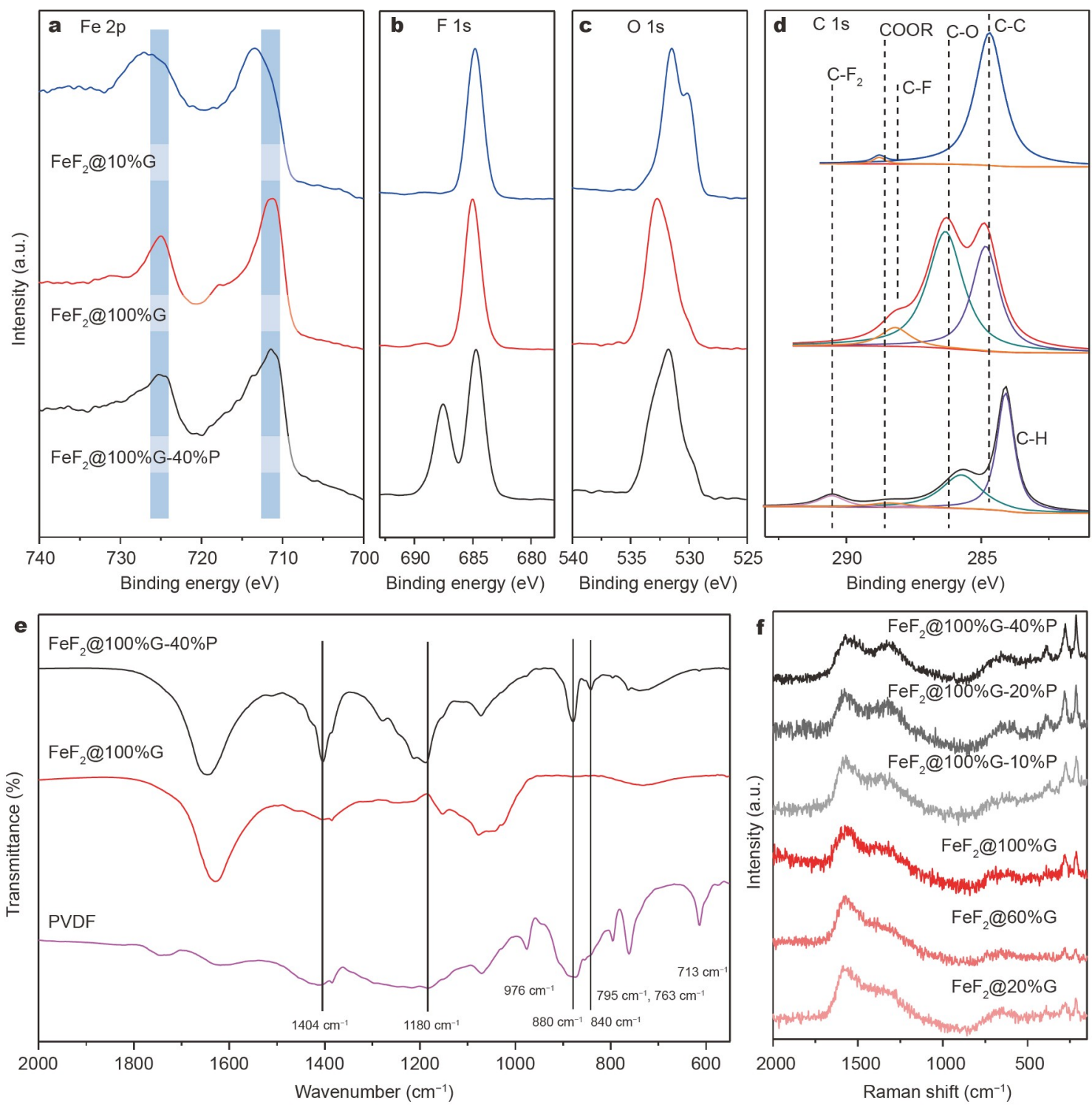

Figure 3 (a) Fe 2p, (b) F 1s, (c) O 1s and (d) C 1s XPS spectra; (e) FTIR spectra of PVDF, FeF $F_{2} 100 \% \mathrm{G}$ and FeF $@ 100 \% \mathrm{G}-40 \% \mathrm{P}$; and (f) Raman spectra of $\mathrm{FeF}_{2} @ x \% \mathrm{G}$ and $\mathrm{FeF}_{2} @ x \% \mathrm{G}-y \% \mathrm{P}$.

peaks at $\sim 685$ and $\sim 687 \mathrm{eV}$, which are attributed to the $\mathrm{FeF}_{2}$ and $\mathrm{C}-\mathrm{F}$ bonds. The $\mathrm{C} 1 \mathrm{~s}$ core level spectra show rich chemical properties, and its spectrum can be resolved into several components corresponding to different chemical bonds. The peak at $\sim 284$ to $\sim 285 \mathrm{eV}$ is attributed to the $\mathrm{C}-\mathrm{H}$ bond or the $\mathrm{C}-\mathrm{C}$ bond. The strong peak at $286.2 \mathrm{eV}$ comes from the $\mathrm{C}-\mathrm{O}$ bond, probably from the glucose in the raw material. Compared with materials without PVDF, the peak at $290.6 \mathrm{eV}$ should be derived from $\mathrm{CF}_{2}$. Four groups of PVDF were planned in different proportions, which were $10 \%, 20 \%, 40 \%$, and $60 \%$, and the excess PVDF formed a tough film during the deposition and cooling of the bottom of the reactor when the feed was higher than $60 \%$. According to the inductively coupled plasma optical emission spectrometry results, the active material $\mathrm{FeF}_{2}$ added to the $40 \%$ composite material was the lowest ( $69.5 \mathrm{wt} \%$ ), and the content of $\mathrm{FeF}_{2}$ in the $20 \%$ and $60 \%$ composite material was above $80 \mathrm{wt} \%$. The highest $\mathrm{FeF}_{2}$ content could reach $93.5 \%$. The chemical state of PVDF in the composites was characterized by
Fourier transform infrared spectrometry (FTIR) (Fig. 3e). One can see that the PVDF infrared characteristic peak after the reaction has the opposite trend to that of the initial PVDF. Specifically, the vibration absorption peak of $\mathrm{O}-\mathrm{C}-\mathrm{O}$ corresponding to $1404 \mathrm{~cm}^{-1}$ and the stretching vibration absorption peak of $\mathrm{CF}_{2}$ corresponding to $1180 \mathrm{~cm}^{-1}$ were enhanced $[25,26]$. The vibrational absorption peaks of the crystalline phases at 976 , 795,763 , and $713 \mathrm{~cm}^{-1}$ disappeared, while the characteristic absorption peaks of the amorphous phases at 880 and $840 \mathrm{~cm}^{-1}$ increased [27]. Moreover, the Raman spectrum of the composite material shows two bands near $1360 \mathrm{~cm}^{-1}$ (D band) and $1600 \mathrm{~cm}^{-1}$ ( $\mathrm{G}$ band) (Fig. 3f). The strength of the D-band increased with the increase in the amount of PVDF added, indicating that more defects or voids were formed in the material. Initial PVDF, $\mathrm{FeF}_{2} @ 100 \% \mathrm{G}$ and $\mathrm{FeF}_{2} @ 100 \% \mathrm{G}-40 \% \mathrm{P}$ containing the same mass of PVDF were dispersed/dissolved in $\mathrm{N}$-methyl pyrrolidone (NMP) solvent. After $72 \mathrm{~h}$ of stirring, the pure NMP and NMP solutions with initial PVDF, FeF $2 @ 100 \% \mathrm{G}$ 
and $\mathrm{FeF}_{2} @ 100 \% \mathrm{G}-40 \% \mathrm{P}$ had visible viscosity differences (Fig. S3). The surface areas of $\mathrm{FeF}_{2} @ 100 \% \mathrm{G}$ and $\mathrm{FeF}_{2} @ 100 \% \mathrm{G}$ $40 \% \mathrm{P}$ were studied by the nitrogen isothermal adsorption technique (Fig. S4), and the results showed that the surface areas of $\mathrm{FeF}_{2} @ 100 \% \mathrm{G}-40 \% \mathrm{P}$ and $\mathrm{FeF}_{2} @ 100 \% \mathrm{G}$ were 59.643 and $92.689 \mathrm{~m}^{2} \mathrm{~g}^{-1}$, respectively, which may be due to the PVDF buffer layer increasing the particle size and filling the gaps between the particles. The organic structure created by PVDF may improve the ion conductivity of the electrode and facilitate the migration of $\mathrm{Li}^{+}$.

\section{Electrochemical performances of the electrodes}

The electrochemical performances of the electrodes were evaluated by galvanostatic charge/discharge measurements. The initial lithiation/delithiation profiles of the $\mathrm{FeF}_{2} @ 100 \% \mathrm{G}$, FeF $@ 100 \% G-10 \%$ P, FeF $F_{2} @ 100 \% G-20 \% \mathrm{P}, \mathrm{FeF}_{2} @ 100 \% \mathrm{G}-40 \% \mathrm{P}$, and $\mathrm{FeF}_{2} @ 100 \% \mathrm{G}-60 \% \mathrm{P}$ electrodes at $100 \mathrm{~mA} \mathrm{~g}^{-1}$ are shown in Fig. S5. The initial coulombic efficiencies (ICEs) of the $\mathrm{FeF}_{2} @ 100 \% \mathrm{G}, \quad \mathrm{FeF}_{2} @ 100 \% \mathrm{G}-10 \% \mathrm{P}, \quad \mathrm{FeF}_{2} @ 100 \% \mathrm{G}-20 \% \mathrm{P}$, $\mathrm{FeF}_{2} @ 100 \% \mathrm{G}-40 \% \mathrm{P}$, and $\mathrm{FeF}_{2} @ 100 \% \mathrm{G}-60 \% \mathrm{P}$ electrodes were $44.1 \%, 51.6 \%, 53.6 \%, 55.0 \%$, and $42.3 \%$, respectively. The $\mathrm{FeF}_{2} @ 100 \% \mathrm{G}-40 \% \mathrm{P}$ electrode showed the highest ICE of $55.0 \%$ due to its thin and uniform PVDF layer reducing side reactions during the process of lithiation.

The specific discharge capacities of the $\mathrm{FeF}_{2}$ with different glucose feed ratios at $100 \mathrm{~mA} \mathrm{~g}^{-1}$ shown in (Fig. 4a) indicate that $\mathrm{FeF}_{2} @ 100 \% \mathrm{G}$ has a discharge capacity of $463.38 \mathrm{~mA} \mathrm{~h}^{-1}$ and maintains $121.26 \mathrm{mAhg}^{-1}$ after 100 cycles, while $\mathrm{FeF}_{2} @ 60 \% \mathrm{G}$ and $\mathrm{FeF}_{2} @ 150 \% \mathrm{G}$ present 45.22 and $96.16 \mathrm{~mA} \mathrm{~h} \mathrm{~g}^{-1}$, respectively. In addition, a cliff decay occurred in cluster-like $\mathrm{FeF}_{2} @ 20 \% \mathrm{G}$ within the first 20 cycles, which had the highest capacity of $669.87 \mathrm{~mA} \mathrm{~h} \mathrm{~g}^{-1}$ at the first discharge cycle and a lower capacity of $27.79 \mathrm{~mA} \mathrm{~h} \mathrm{~g}^{-1}$ at the $20^{\text {th }}$ cycle, indicating that not all special structures could increase the electrochemical performance of the positive electrode; however, the capacity was greatly reduced due to the collapse of the structure during the charge/discharge cycle. The galvanostatic charge/discharge measurements of the electrode materials with different ratios of PVDF at $100 \mathrm{mAg}^{-1}$ at $25^{\circ} \mathrm{C}$ are listed in Fig. $4 \mathrm{~b}$. The results show that insufficient PVDF caused a decaying performance, such as $\mathrm{FeF}_{2} @ 20 \% \mathrm{G}$. The gaps between the nanoparticles are unevenly filled with viscous PVDF, which may induce the squeezing and shedding of the active particles during the volume changes caused by the charge/ discharge process, and lead to poor electronic conductivity and low capacity retention, along with larger volume changes and greater polarization with higher currents, so the specific capacity is reduced to below $10 \mathrm{~mA} \mathrm{~h} \mathrm{~g}^{-1}$ after 20 cycles at $100 \mathrm{~mA} \mathrm{~g}^{-1}$ in the rate test.

$\mathrm{FeF}_{2} @ 100 \% \mathrm{G}-40 \% \mathrm{P}$ with the best performance has a specific capacity of $314.42 \mathrm{mAhg}^{-1}$ after 100 cycles with a starting capacity of $404.26 \mathrm{~mA} \mathrm{~h} \mathrm{~g}^{-1}$ (based on the active material, $\mathrm{FeF}_{2}$ ), which is significantly higher than the capacity of other proportions of PVDF active materials. A high coincidence rate curve and the efficiency close to $100 \%$ are observed from the charge/
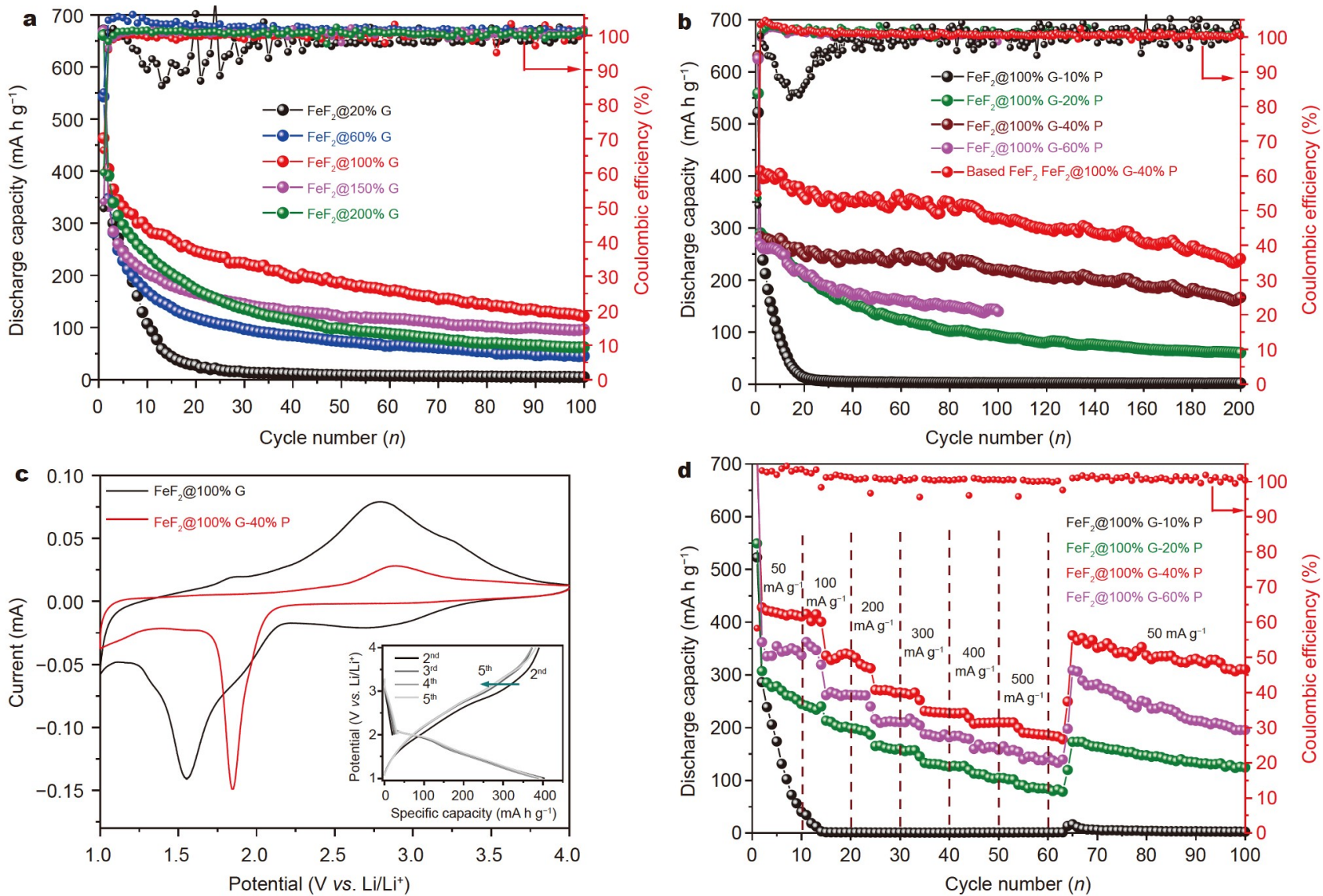

Figure 4 Gravimetric specific discharge capacities and coulombic efficiency of (a) $\mathrm{FeF}_{2} @ x \% \mathrm{G}$ and (b) FeF $@ x \% \mathrm{G}-y \% \mathrm{P}$. The electrode was charged/ discharged between 1.0 and $4.0 \mathrm{~V}\left(v s . \mathrm{Li}^{+} / \mathrm{Li}\right.$ ) at $100 \mathrm{~mA} \mathrm{~g}{ }^{-1}$; (c) $\mathrm{CV}$ of $\mathrm{FeF}_{2} @ 100 \% \mathrm{G}$ and $\mathrm{FeF}_{2} @ 100 \% \mathrm{G}-40 \% \mathrm{P}$ electrodes from 1 to $4 \mathrm{~V}$ (rate cycling of the $\mathrm{FeF}_{2} @ 100 \% \mathrm{G}-40 \% \mathrm{P}$ electrodes inside); (d) galvanostatic charge/discharge profiles of the FeF $\mathrm{F}_{2} @ x \% \mathrm{G}-y \% \mathrm{P}$ electrodes. 

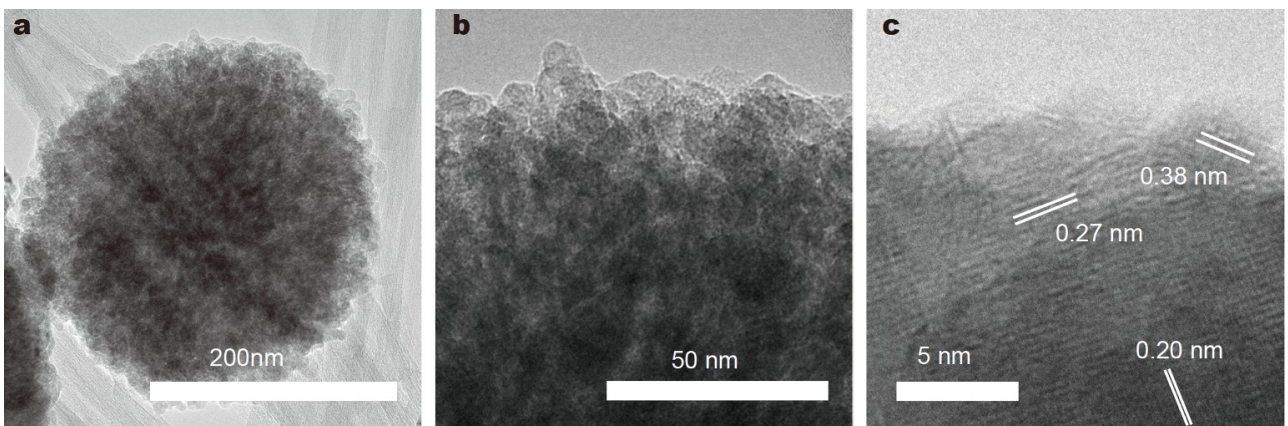

Figure 5 (a, b) TEM and (c) HRTEM of $\mathrm{FeF}_{2} @ 100 \% \mathrm{G}-40 \% \mathrm{P}$ after 200 cycles.

discharge curve of $\mathrm{FeF}_{2} @ 100 \% \mathrm{G}-40 \% \mathrm{P}$ in the second to fifth cycles, as shown in Fig. 4c. In addition, when the amount of PVDF was increased to $60 \%$, the poor stability exhibited by the $\mathrm{FeF}_{2} @ 100 \% \mathrm{G}-60 \% \mathrm{P}$ electrode and the charge-discharge specific capacity was lower than those of $\mathrm{FeF}_{2} @ 100 \% \mathrm{G}-60 \% \mathrm{P}$, which was attributed to excess PVDF deposition. The oligomeric microspheres hinder the migration of $\mathrm{Li}^{+}$and significantly reduce its cycling performance.

Two lithiated regions during discharge represent the intercalation reaction and the conversion reaction. The first region should form $\mathrm{Li}_{x} \mathrm{Fe}_{2-x} \mathrm{~F}_{2}$ from the open-circuit voltage to $2.0 \mathrm{~V}$ with the insertion of $\mathrm{Li}$ ions into $\mathrm{Fe}^{3+}$ impurities from some $\mathrm{Fe}^{2+}$ oxidized by exposure to air. Due to the functionalization of the particle surface and the protection of the PVDF buffer layer, the first region is nearly vertical and shows a discharge capacity of $20 \mathrm{~mA} \mathrm{~h} \mathrm{~g}^{-1}$, indicating that there was no significant lithium intercalation reaction. The second lithiated region is a redox platform below $2 \mathrm{~V}$, ascribed to the conversion reaction of $\mathrm{FeF}_{2}$ to $\alpha$-Fe. Combining the CVs of $\mathrm{FeF}_{2} @ 100 \% \mathrm{G}$ and $\mathrm{FeF}_{2} @ 100 \% \mathrm{G}-$ $40 \% \mathrm{P}$, it can be observed that the presence of PVDF increases the voltage of the electrode material and that the increase of the discharge current guides the sharpness of the discharge peak. During the delithiation process (charging), $\mathrm{FeF}_{2} @ 100 \% \mathrm{G}-40 \% \mathrm{P}$ showed a single wide peak at $2.9 \mathrm{~V} v s . \mathrm{Li} / \mathrm{Li}^{+}$and contributed almost half of the capacitance. In contrast, the charging curve of $\mathrm{FeF}_{2} @ 100 \% \mathrm{G}$ fluctuates greatly, and the charging current shows a substantial rising trend before the peak of $2.75 \mathrm{~V}$.

To highlight the ability of $\mathrm{FeF}_{2} @ 100 \% \mathrm{G}-40 \% \mathrm{P}$ to improve the electrochemical performance of $\mathrm{FeF}_{2}$ electrode materials, charge and discharge tests were performed at different rates (Fig. $4 \mathrm{~d}$ ). The FeF $\mathrm{F}_{2} @ 100 \% \mathrm{G}-40 \% \mathrm{P}$ electrode exhibited specific discharge capacities of 228.17 and $186.59 \mathrm{~mA} \mathrm{~h} \mathrm{~g}^{-1}$ at currents of 300 and $500 \mathrm{~mA} \mathrm{~g}^{-1}$, reaching $56 \%$ and $46 \%$ of $100 \mathrm{~mA} \mathrm{~g}^{-1}$, respectively. After rate cycling, the electrode could still recover a discharge capacity of $375 \mathrm{~mA} \mathrm{~h} \mathrm{~g}^{-1}$ under a current of $50 \mathrm{~mA} \mathrm{~g}^{-1}$. The high stability of the electrode material under a large current could be confirmed by the prominent discharge peak in the CV diagram. $\mathrm{FeF}_{2} @ 100 \% \mathrm{G}-20 \% \mathrm{P}$ and $\mathrm{FeF}_{2} @ 100 \% \mathrm{G}-60 \% \mathrm{P}$ are relatively weak, showing only 84 and $144.95 \mathrm{~mA} \mathrm{~h} \mathrm{~g}^{-1}$ at a current of $500 \mathrm{~mA} \mathrm{~g}^{-1}$. Returning to $50 \mathrm{~mA} \mathrm{~g}^{-1}$ after 30 cycles, the $\mathrm{FeF}_{2} @ 100 \% \mathrm{G}-20 \% \mathrm{P}$ and $\mathrm{FeF}_{2} @ 100 \% \mathrm{G}-60 \% \mathrm{P}$ electrodes decreased rapidly to 125 and $200 \mathrm{mAhg}^{-1}$, respectively. The $\mathrm{FeF}_{2} @ 100 \% \mathrm{G}-40 \% \mathrm{P}$ electrode has higher capacity, rate performance, and cycle stability, indicating that equivalent PVDF can improve the stability of the electrode and help it charge/discharge quickly.

Electrochemical impedance spectroscopy (EIS) was used to investigate the electrochemical performance of various electrodes after 25 and 50 cycles in the delithiation state. As shown in Fig. S6, the $\mathrm{FeF}_{2} @ 100 \% \mathrm{G}$ and $\mathrm{FeF}_{2} @ 100 \% \mathrm{G}-10 \% \mathrm{P}$ electrodes showed strong internal resistance after 50 cycles compared with the first cycle. At the same time, the impedance spectra of the FeF $@ 100 \% G-20 \%$ P, FeF $F_{2} @ 100 \% G-40 \%$ P, and $\mathrm{FeF}_{2} @ 100 \% \mathrm{G}-$ $60 \% \mathrm{P}$ electrodes remained essentially unchanged after 50 cycles. In particular, the $\mathrm{FeF}_{2} @ 100 \% \mathrm{G}-40 \% \mathrm{P}$ electrode showed the smallest semicircle compared with the other electrodes after 50 cycles, implying the smallest charge transfer resistance and fastest ion diffusivity.

TEM was performed on the positive electrode material after 200 cycles. The cathode material after cycling retains its morphology before cycling and it has a smaller particle size. In HRTEM scanning, there are three kinds of crystal lattices with obvious size differences: $0.38 \mathrm{~nm}\left(\mathrm{FeF}_{3}\right), 0.27 \mathrm{~nm}\left(\mathrm{FeF}_{2}\right)$, and $0.20 \mathrm{~nm}(\mathrm{Fe})$ (Fig. 5). The lattice of $0.20 \mathrm{~nm}$ was concentrated inside the particle, mainly due to the uneven aggregation of $\mathrm{Fe}$ nanoparticles and LiF during the discharge process. The $0.38 \mathrm{~nm}$ crystal lattice appears on the surface of the particles, which is due to the pseudocapacitive effect caused by the increase in $\mathrm{Fe}$ valence due to overcharge/discharge. Together, these factors cause a small amount of battery capacity loss during cycling.

Based on the above analyses, FeF $@ 100 \%$ G-40\%P has better cycle stability and rate performance, which can be attributed to the structural protection of PVDF gelation. The open, plastic thin walls attenuate the volume expansion and collapse of the material and allow the material to have better cycle stability than $\mathrm{FeF}_{2} @ 100 \% \mathrm{G}$. In particular, the introduction of PVDF forms a buffer layer on the surface of the particles, effectively restraining the volume expansion and improving organic electrolyte wettability. After 200 cycles, the high adhesion ability enables excellent electrical contact between the particles and conductive agent, inhibiting particle agglomeration. The small size of $\mathrm{FeF}_{2}$ particles can shorten the electron transmission distance, thereby achieving high capacity utilization and small voltage hysteresis.

\section{CONCLUSIONS}

In summary, a special material that can be used for LIB cathodes was prepared using glucose reduction by a solvothermal method. Electrochemical testing showed that high-rate performance and cyclic capacity could be implemented by introducing a suitable amount of PVDF, which caused a stable structure to buffer volume change and supported a thin and conformal layer. The $\mathrm{FeF}_{2} @ 100 \% \mathrm{G}-40 \% \mathrm{P}$ electrode exhibited a robust cycling performance of $313 \mathrm{~mA} \mathrm{~h} \mathrm{~g}^{-1}$ after 150 cycles at $100 \mathrm{~mA} \mathrm{~g}^{-1}$ and a 
high rate capacity of $186.59 \mathrm{~mA} \mathrm{~h} \mathrm{~g}^{-1}$ at $500 \mathrm{~mA} \mathrm{~g}^{-1}$. The superior performance of the cathodes provides an effective way to prepare materials with high energy density for LIBs.

\section{Received 27 May 2021; accepted 16 August 2021;}

published online 24 September 2021

1 Armand M, Tarascon JM. Building better batteries. Nature, 2008, 451: 652-657

2 Larcher D, Tarascon JM. Towards greener and more sustainable batteries for electrical energy storage. Nat Chem, 2015, 7: 19-29

3 Zhou L, Yao L, Li S, et al. The combination of intercalation and conversion reactions to improve the volumetric capacity of the cathode in Li-S batteries. J Mater Chem A, 2019, 7: 3618-3623

4 He J, Chen Y, Lv W, et al. Three-dimensional hierarchical grapheneCNT@Se: A highly efficient freestanding cathode for Li-Se batteries. ACS Energy Lett, 2016, 1: 16-20

5 Wang F, Kim SW, Seo DH, et al. Ternary metal fluorides as highenergy cathodes with low cycling hysteresis. Nat Commun, 2015, 6: 6668

6 Wu F, Yushin G. Conversion cathodes for rechargeable lithium and lithium-ion batteries. Energy Environ Sci, 2017, 10: 435-459

7 Gordon D, Huang Q, Magasinski A, et al. Mixed metal difluorides as high capacity conversion-type cathodes: Impact of composition on stability and performance. Adv Energy Mater, 2018, 8: 1800213

8 Wang $\mathrm{X}, \mathrm{Gu}$ W, Lee JT, et al. Carbon nanotube- $\mathrm{CoF}_{2}$ multifunctional cathode for lithium ion batteries: Effect of electrolyte on cycle stability. Small, 2015, 11: 5164-5173

9 Badway F, Mansour AN, Pereira N, et al. Structure and electrochemistry of copper fluoride nanocomposites utilizing mixed conducting matrices. Chem Mater, 2007, 19: 4129-4141

10 Schütte K, Barthel J, Endres M, et al. Synthesis of metal nanoparticles and metal fluoride nanoparticles from metal amidinate precursors in 1butyl-3-methylimidazolium ionic liquids and propylene carbonate. ChemistryOpen, 2017, 6: 137-148

11 Badway F, Cosandey F, Pereira N, et al. Carbon metal fluoride nanocomposites. J Electrochem Soc, 2003, 150: A1318

12 Prakash R, Mishra AK, Roth A, et al. A ferrocene-based carbon-iron lithium fluoride nanocomposite as a stable electrode material in lithium batteries. J Mater Chem, 2010, 20: 1871-1876

13 Zhou J, Zhang D, Zhang X, et al. Carbon-nanotube-encapsulated $\mathrm{FeF}_{2}$ nanorods for high-performance lithium-ion cathode materials. ACS Appl Mater Interfaces, 2014, 6: 21223-21229

14 Zhang Y, Wang L, Li J, et al. A one-pot approach towards $\mathrm{FeF}_{2}$-carbon core-shell composite and its application in lithium ion batteries. J Alloys Compd, 2014, 606: 226-230

15 Reddy MA, Breitung B, Chakravadhanula VSK, et al. $\mathrm{CF}_{x}$ derived carbon- $\mathrm{FeF}_{2}$ nanocomposites for reversible lithium storage. Adv Energy Mater, 2013, 3: 308-313

16 Huang Q, Turcheniuk K, Ren X, et al. Insights into the effects of electrolyte composition on the performance and stability of $\mathrm{FeF}_{2}$ conversion-type cathodes. Adv Energy Mater, 2019, 9: 1803323

$17 \mathrm{Gu} \mathrm{W}$, Borodin O, Zdyrko B, et al. Lithium-iron fluoride battery with in situ surface protection. Adv Funct Mater, 2016, 26: 1507-1516

18 Xiao AW, Lee HJ, Capone I, et al. Understanding the conversion mechanism and performance of monodisperse $\mathrm{FeF}_{2}$ nanocrystal cathodes. Nat Mater, 2020, 19: 644-654

$19 \mathrm{Wu}$ S, Su B, Ni K, et al. Fluorinated carbonate electrolyte with superior oxidative stability enables long-term cycle stability of $\mathrm{Na}_{2 / 3} \mathrm{Ni}_{1 / 3} \mathrm{Mn}_{2 / 3} \mathrm{O}_{2}$ cathodes in sodium-ion batteries. Adv Energy Mater, 2021, 11: 2002737

20 Huang Q, Turcheniuk K, Ren X, et al. Cycle stability of conversion-type iron fluoride lithium battery cathode at elevated temperatures in polymer electrolyte composites. Nat Mater, 2019, 18: 1343-1349

21 Ding J, Zhou X, Wang $\mathrm{H}$, et al. Mn-doped $\mathrm{Fe}_{1-x} \mathrm{Mn}_{x} \mathrm{~F}_{3} \cdot 0.33 \mathrm{H}_{2} \mathrm{O} / \mathrm{C}$ cathodes for Li-ion batteries: First-principles calculations and experimental study. ACS Appl Mater Interfaces, 2019, 11: 3852-3860

22 Wei $\mathrm{S}$, Wang $\mathrm{X}$, Yu R, et al. Ti-doped $\mathrm{Fe}_{1-x} \mathrm{Ti}_{x} \mathrm{~F}_{3} \cdot 0.33 \mathrm{H}_{2} \mathrm{O} / \mathrm{C}$ nanocomposite as an ultrahigh rate capability cathode materials of lithium ion batteries. J Alloys Compd, 2017, 702: 372-380

23 Sun $\mathrm{H}$, Zhou $\mathrm{H}, \mathrm{Xu} \mathrm{Z}$, et al. Preparation of anhydrous iron fluoride with porous fusiform structure and its application for Li-ion batteries. Microporous Mesoporous Mater, 2017, 253: 10-17

24 Wang Y, Zhao J, Zhu Y, et al. Controlled fabrication and optical properties of 3D hierarchical $\alpha-\mathrm{Bi}_{2} \mathrm{O}_{3}$ siamesed microflowers. Colloids Surfs A-Physicochem Eng Aspects, 2013, 434: 296-302

25 Rajati H, Navarchian AH, Tangestaninejad S. Preparation and characterization of mixed matrix membranes based on matrimid/PVDF blend and MIL-101(Cr) as filler for $\mathrm{CO}_{2} / \mathrm{CH}_{4}$ separation. Chem Eng Sci, 2018, 185: 92-104

26 Kayal S, Sun B, Chakraborty A. Study of metal-organic framework MIL-101(Cr) for natural gas (methane) storage and compare with other MOFs (metal-organic frameworks). Energy, 2015, 91: 772-781

27 Zak AK, Gan WC, Majid WHA, et al. Experimental and theoretical dielectric studies of PVDF/PZT nanocomposite thin films. Ceramics Int, 2011, 37: 1653-1660

Acknowledgements This work was supported by the Science and Technology Commission of Shanghai Municipality (20520710400, 19JC1412600 and 18230743400), the National Natural Science Foundation of China (21771124 and 21901156), the Oceanic Interdisciplinary Program (SL2020MS020), and the SJTU-Warwick Joint Seed Fund (2019/20) of Shanghai Jiao Tong University.

Author contributions Chen $\mathrm{M}$ designed and engineered the materials; Zhao L characterized the battery performances; Zhao L, Li X and Liu X contributed to the data analyses and discussion; Chen $\mathrm{M}$ wrote the paper with support from Zai J, Qi R, and Qian X. All authors contributed to the general discussion.

Conflict of interest The authors declare that they have no conflict of interest.

Supplementary information Supporting data are available in the online version of the paper.

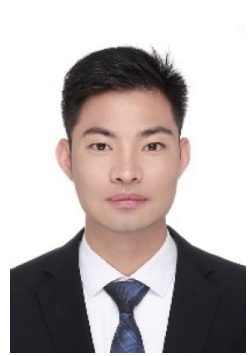

Ming Chen received his BE degree in 2014 from Jiujiang University and ME degree in 2018 from Shanghai Normal University. $\mathrm{He}$ is a $\mathrm{PhD}$ candidate at the School of Chemistry and Chemical Engineering, Shanghai Jiao Tong University. His research interests mainly focus on lithium-ion batteries.

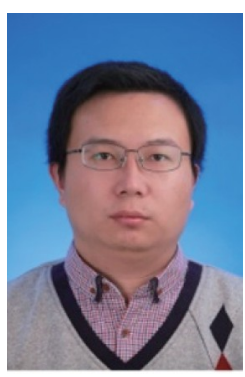

Jiantao Zai received his bachelor (2007) and $\mathrm{PhD}$ (2012) degrees in applied chemistry from Shanghai Jiao Tong University, then worked with Prof. Donghai Wang at Penn State University. He joined Shanghai Jiao Tong University as a lecturer in 2014. His research interests include the synthesis chemistry of group IV inorganic materials and their potential applications in energy storage, photovoltaic and photocatalytic areas. 


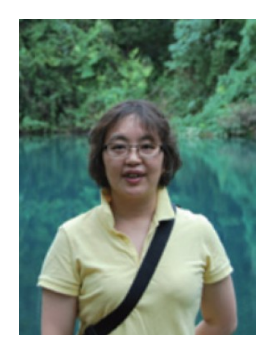

Rongrong Qi received her bachelor degree from Hefei University of Technology, master and $\mathrm{PhD}$ degrees from the University of Science and Technology of China. Her research interests include polymers and inorganic nanocomposites.

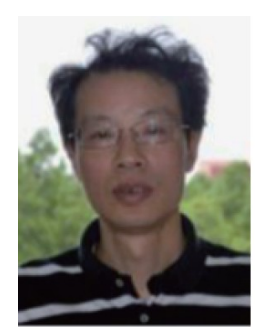

Xuefeng Qian is a professor and vice dean of the School of Chemistry and Chemical Engineering and a faculty at the State Key Laboratory of Metal Matrix Composites, Shanghai Jiao Tong University. His research interests include structure design, controlled synthesis, modification, and applications of nanomaterials in energy storage and solar energy utilization. He received his bachelor degree in polymer material science (1990) from Hefei University of Technology, master degree (1995) in polymer material science and $\mathrm{PhD}$ degree (1998) in inorganic chemistry from the University of Science and Technology of China.

\section{人工正极固体电解质膜赋予 $\mathrm{FeF}_{2}$ 纳米晶正极材料良 好的储锂循环稳定性}

陈明, 赵亮, 李晓敏, 刘雪娇, 宰建陶", 戚嵘嵘, 钱雪峰*

摘要 氟化亚铁被认为是锂离子电池的高容量正极材料. 然而, 由于转 换反应的电化学动力学不佳, 它们的比容量和稳定性受到很大限制. 如 果将转换反应限域在纳米空间中, 可有效避免由于活性物质的长大而 导致的失活. 本文中, 我们通过葡萄糖还原和聚偏氟乙烯原位包覆的方 法, 在 $\mathrm{FeF}_{2}$ 纳米晶体表面构建了一层聚偏氟乙烯基人工正极固体电解 质膜(CEI)(材料定义为 $\mathrm{FeF}_{2} @ 100 \% \mathrm{G}-40 \% \mathrm{P}$ ). 由于纳米限域空间改善了 转化反应的动力学, 抑制了纳米晶长大, 所获得的 $\mathrm{FeF}_{2} @ 100 \% \mathrm{G}-40 \% \mathrm{P}$ 电 极显示出良好的循环稳定性(在 $100 \mathrm{~mA} \mathrm{~g}^{-1}$ 的电流密度下, 循环 150 次比 容量为 $313 \mathrm{~mA} \mathrm{~h} \mathrm{~g}^{-1}$, 容量保持率为 $80 \%$ ) 和高倍率性能(在 $500 \mathrm{~mA} \mathrm{~g}^{-1}$ 的 电流密度下, 比容量为 $186.6 \mathrm{~mA} \mathrm{~h} \mathrm{~g}^{-1}$ ). 